PROCEEDINGS, Twenty-Third Workshop on Geothermal Reservair Engineering

Stanford University, Stanford, California, January 26-28, 1998

SGP-TR-158

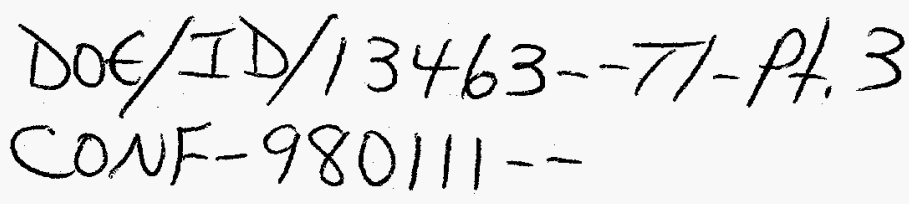

\title{
RESERVOIR-SCALE FRACTURE PERMEABILITY IN THE DIXIE VALLEY, NEVADA, GEOTHERMAL FIELD
}

\author{
Colleen A Barton', Stephen Hickman², Roger Morin', \\ Mark D. Zoback ${ }^{2}$, and Dick Benoit ${ }^{4}$ \\ 'Stanford University, Dept. of Geophysics, Stanford, CA 94305, USA \\ barton@pangea.stanford.edu, zoback@pangea.stanford.edu \\ ${ }^{2}$ U.S. Geological Survey, Menlo Park, CA 94025, USA \\ hickman@thepub.wr.usgs.gov \\ ${ }^{3}$ U.S. Geological Survey, Denver, CO 80225, USA \\ rhmorin@borehole.cr.usgs.gov \\ ${ }^{4}$ Oxbow Geothermal Corp., Reno, NV 89502, USA \\ dick_benoit@opsi.oxbow.com
}

\begin{abstract}
Wellbore image data recorded in six wells penetrating a geothermal reservoir associated with an active normal fault at Dixie Valley, Nevada, were used in conjunction with hydrologic tests (Morin et al., this volume) and in situ stress measurements (Hickman and Zoback, this volume) to investigate the relationship between reservoir productivity and the contemporary in situ stress field.

Our analysis of data from wells drilled into productive and non-productive segments of the Stillwater fault zone indicates that fractures must be both optimally oriented and critically stressed to have high measured permeabilities. Fracture permeability in all wells is dominated by a relatively small number of fractures oriented parallel to the local trend of the Stillwater Fault. Fracture geometry may also play a significant role in reservoir productivity. The well-developed populations of low angle fractures present in wells drilled into the producing segment of the fault are not present in the zone where production is not commercially viable.
\end{abstract}

\section{INTRODUCTION}

The Dixie Valley Geothermal Field is a faultcontrolled geothermal reservoir located in the Basin and Range Province of the Western United States. The Stillwater Fault, a basin bounding normal fault, is the producing reservoir for a geothermal plant operated by Oxbow Geothermal Corporation. However, there are well-documented lateral variations in productivity along the fault that are not fully understood.

Hickman and Zoback (this volume), Hickman et al., 1997 and Barton et al., (1997) introduce the project background, study objectives and review the results of previous studies. This paper presents the most recent results of our analysis of the fractured-rock hydrology within and outside the producing reservoir at Dixie Valley. The data discussed herein represents an ongoing integrated study of the relationship between crustal fluid flow and the contemporary insitu stress field.

\section{DATA ACQUISITION AND ANALYSIS}

The initial field work for our study was completed in the fall of 1995 when we obtained data from well $73 \mathrm{~B}-7$, drilled $2640 \mathrm{~m}$ into the producing segment of the Stillwater fault. The remaining field work for this study was completed during an extensive reservoir-scale open-hole logging program from October 1996 through April 1997. In this second phase of field work we obtained sets of borehole televiewer (BHTV), precision temperature, and spinner flowmeter logs from two additional wells within the primary zone of geothermal production (transmissivities on the order of $1 \mathrm{~m}^{2} / \mathrm{min}$ ) and from three wells within a few $\mathrm{km}$ of the producing zone that were relatively impermeable and, hence, not commercially viable (transmissivities of about $10^{-4}$ $\mathrm{m}^{2} / \mathrm{min}$ ). Using these logs, we have located and oriented faults and fractures and studied their hydrologic properties through comparison with 
fracture-related thermal and flow anomalies. The measurements made in these wells provide complete data for a systematic, comparative study of the effects of in situ stress on fracture permeability along producing and non-producing segments of the fault.

Wellbore image data acquisition required an extended field program to cope with the hostile logging

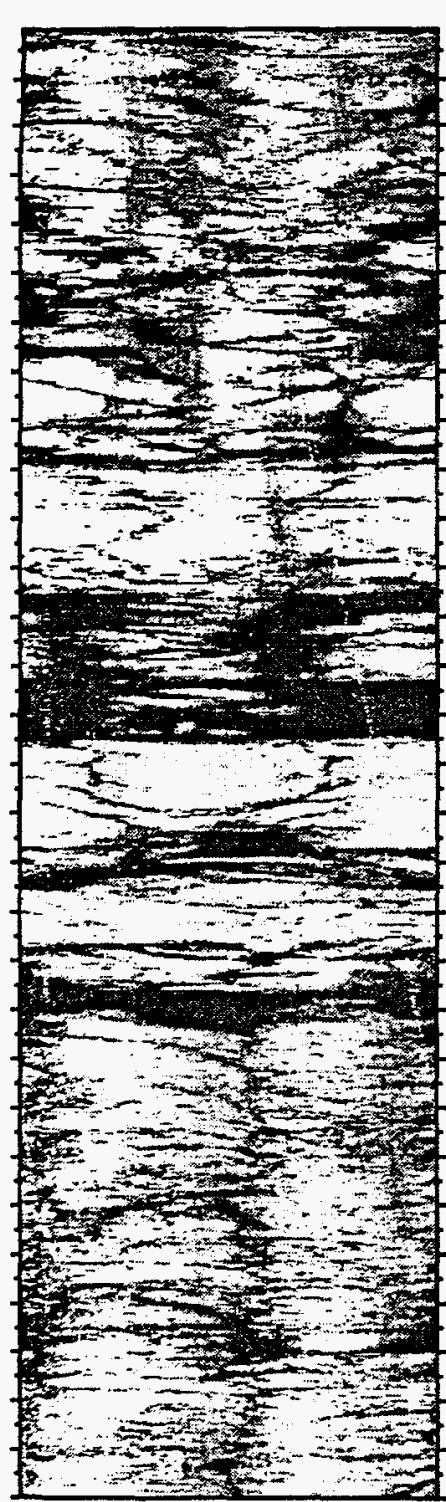

a)

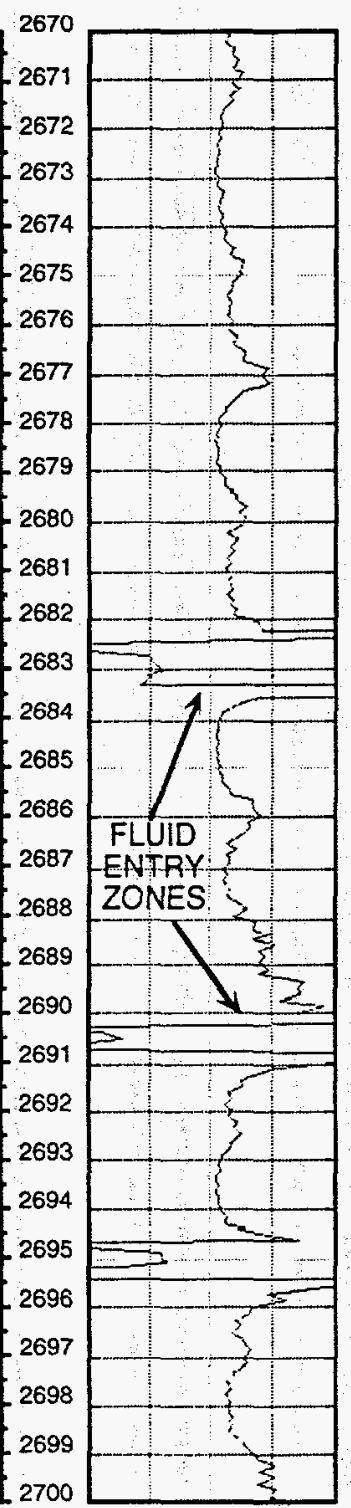

b)
Figure 1. (a) High Temperature Borehole televiewer data recorded over the interval $2670-2700 \mathrm{~m}$ in well 37-33 located in the producing reservoir at Dixie Valley correlated with temperature gradient data recorded over the same interval (b). conditions of the wells (up to $240^{\circ} \mathrm{C}$ temperatures and 3,300 $\mathrm{m}$ depths). The Stanford and USGS hightemperature borehole televiewers were used to $\log$ these wells. Fundamentals of the operation of these acoustic tools are described in detail in Zemanek [1970]. The strike, dip and apparent aperture of the fractures have been measured using the digital BHTV analysis system developed at Stanford University (see Barton et al., 1991).

To date, we have digitized and analyzed approximately 2887 meters of analog BHTV data recorded in the six wells. The depth intervals over which image data were recorded for this study are presented in Table 1. The digital data were calibrated using numerous field calibration checks conducted before and after each logging run according to our standard field procedure. The data were then processed and edited for systematic noise and other tool related problems. An example of the BHTV data obtained in this well is shown in Figure 1a, where several natural fractures (represented as sinusoids) cross-cut the borehole.

\begin{tabular}{|c|c|c|}
\hline $\begin{array}{c}\text { WEL } \\
\text { NAME }\end{array}$ & $\begin{array}{c}\text { DEPTH INTERVAL } \\
\text { meters }\end{array}$ & $\begin{array}{c}\text { FRACTURE } \\
\text { POPULATION }\end{array}$ \\
\hline $73 \mathrm{~B}-7$ & $1850-2640$ & $\mathrm{n}=653$ \\
\hline $74-7$ & $2590-2740$ & $\mathrm{n}=49$ \\
\hline $37-33$ & $2624-2826$ & $\mathrm{n}=694$ \\
\hline $62-21$ & $2600-3330$ & $\mathrm{n}=672$ \\
\hline $66-21$ & $2200-2770$ & $\mathrm{n}=1213$ \\
\hline $45-14$ & $2280-2725$ & $\mathrm{n}=1264$ \\
\hline
\end{tabular}

Table 1. Depth intervals and population of natural fractures measured for each study well.

\section{FRACTURE ANALYSIS RESULTS}

Macroscopic fractures are pervasive throughout the logged interval of each of the wells. Analysis of wellbore image data recorded in each well yields a dominant natural fracture population that is parallel to the local trend of the Stillwater Fault.

The orientations of all fractures within the producing reservoir are shown in lower hemisphere stereographic projection of contoured poles to fracture planes (Figure 2, after Kamb, 1959; contour interval $=2.0$ sigma). The fracture populations measured in wells drilled along the producing segment of the Stillwater have significant scatter in orientation but fractures generally become steeper and larger in apparent aperture with depth. The dominant fracture trend is north - northeast with shallow to moderate dips to the 


\section{DISCLAIMER}

This report was prepared as an account of work sponsored by an agency of the United States Government. Neither the United States Government nor any agency thereof, nor any of their employees, makes any warranty, express or implied, or assumes any legal liability or responsibility for the accuracy, completeness, or usefulness of any information, apparatus, product, or process disclosed, or represents that its use would not infringe privately owned rights. Reference herein to any specific commercial product, process, or service by trade name, trademark, manufacturer, or otherwise does not necessarily constitute or impiy its endorsement, recommendation, or favoring by the United States Government or any agency thereof. The views and opinions of authors expressed herein do not necessarily state or reflect those of the United States Government or any agency thereof. 


\section{DISCLAIMER}

Portions of this document may be illegible electronic image products. Images are produced from the best available original document. 


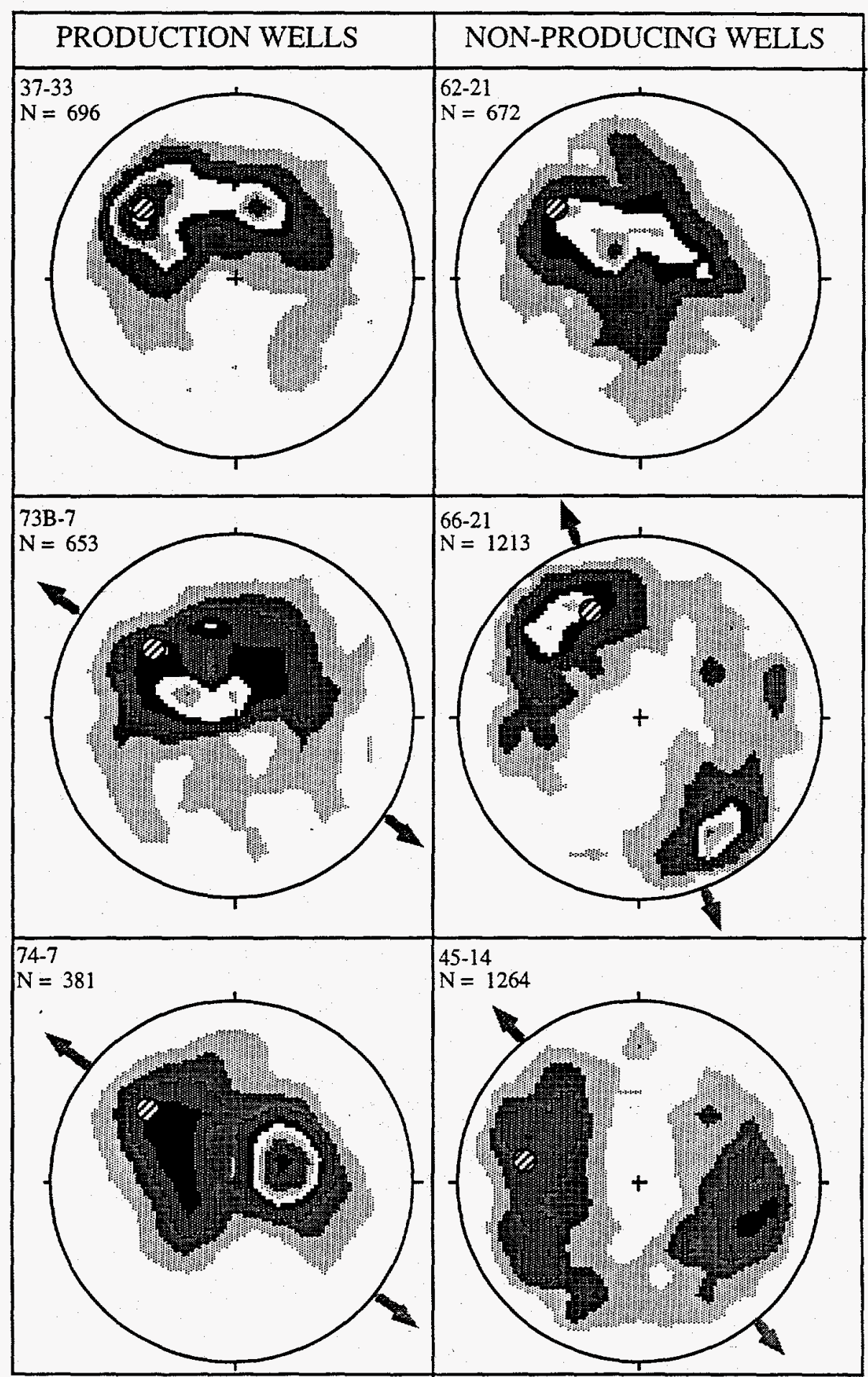

Figure 2. Kamb contours of poles to fracture planes for well drilled into the producing segment of the Stillwater Fault (left column) and contoured poles to planes of fractures measured in wells drilled into the less permeable fault segments (right column). Larger hashed circles represent the pole to the local trend of the Stillwater fault intersected by each study well. Arrows indicate the orientation of $S_{\text {hmin }}$ measured in each well from Hickman and Zoback (this volume). 
east or west (Figure 2). The local orientation of the Stillwater fault [Okaya and Thompson, 1985] is shown for reference as the large hashed circles in these diagrams. There are statistical differences in the orientation of these macroscopic fracture populations measured within the producing field and those measured in non-producing wells located less than a few $\mathrm{km}$ to the southwest.

Wells drilled into the relatively impermeable segments of the Stillwater faults located 8 and $20 \mathrm{~km}$ southwest of the main reservoir show well-developed sets of moderate to steeply dipping fractures. In contrast to the fracture populations measured in wells drilled into the producing fault segments, the nonproductive well have no significant population of low angle fractures. The lack of low angle fractures in these wells may impede fracture connectivity with the reservoir.

\section{FRACTURE AND FLUID FLOW ANALYSIS RESULTS}

Precision temperature and spinner flowmeter logs (referred to as TPS logs) were acquired in the five additional boreholes of this study in the same manner they were recorded in well 73B-7 (Barton, et al., 1997) to provide comparable data sets for all wells. TPS tests were conducted with and without simultaneously injecting water into the well. Fluid flow into or out of individual fractures and faults was determined through an analyses of these temperature and spinner flowmeter logs (see Paillet, 1994). When a borehole is close to thermal equilibrium with the surrounding rock, heat transfer occurs primarily by thermal conduction and the temperature gradient in the borehole is a function of thermal conductivity and heat flux. Localized perturbations to well-bore temperature will result from localized fluid flow into or out of the borehole and can be detected by precision temperature logging. Fractures or faults that correlate in depth with these localized temperature perturbations are therefore considered to be hydraulically conductive. Multi-pass temperature logs at various pumping rates allow us to assess the persistence of these detected flow horizons.

Analysis of TPS and precision temperature logs acquired in these wells under naturally flowing conditions and during injection indicates that hydraulically conductive fractures along the nonproducing segments of the Stillwater fault have much lower permeabilities than observed in wells drilled into the producing fault segments. These data were also analyzed to obtain quantitative measures of permeability over discrete intervals in many of these wells and are reported by Morin et al., (this volume). Wells within the production zone have extremely high bulk permeabilities on the order of $10^{5} \mathrm{mD}-\mathrm{m}$. Well outside of the production zone have permeabilities on the order of $10^{\prime} \mathrm{mD}-\mathrm{m}$.

The depth locations of individual flow anomalies detected in each of the study wells were established through a combined analysis of temperature profiles, temperature gradient profiles, and spinner logs. Multiple passes of the TPS log data were evaluated to determine the variation of these anomalies with various pumping rates. The higher fluid production rates in wells 74-7, 73B-7 and 37-33 enhanced the fluid flow anomalies observed in these wells making them more prominent than anomalies in wells 62 $21,66-21$ and 45-14. However, it was possible to determine the zones of fluid movement in the nonproductive wells utilizing the TPS data from several repeat log runs.

The fracture and fluid flow analysis indicates that in both the producing and non-producing wells there are relatively few fractures that dominate flow. Figure 3 shows the strike direction of the significant producing fractures for each of the study wells along with the orientation of the least horizontal principal stress from Hickman and Zoback (this volume). Orientations of fractures measured in wells drilled into the producing segment of the Stillwater Fault are shown in the left column of Figure 3 and those drilled into non-productive segments are presented in the right column.

Wells 73B-7, 74-7, and 37-33 intersect the producing segment of the Stillwater Fault at 2518 $\mathrm{m}, 2680 \mathrm{~m}$ and $2782 \mathrm{~m}$ respectively. The population of producing fractures in each of these wells clearly defines a distinct subset of the total fracture population in that well that is normal to the local direction of the least horizontal principal stress, $S_{\text {hmin }}$. Stress orientation data from well $37-33$ is scattered due to local perturbations of stress from active slip. We therefore use the more consistent stress orientation data from nearby wells $73 \mathrm{~B}-7$ and 74-7 for our analysis of critically stressed fractures from this well.

Well 62-21 was drilled to a total depth of $3560 \mathrm{~m}$ and may not have intersected the Stillwater Fault. As discussed by Hickman and Zoback (this volume) no in situ stress indicators were detected in this well through image logging. Well $62-21$ is located approximately $2 \mathrm{~km}$ from the producing wells $73 \mathrm{~B}-7$ 


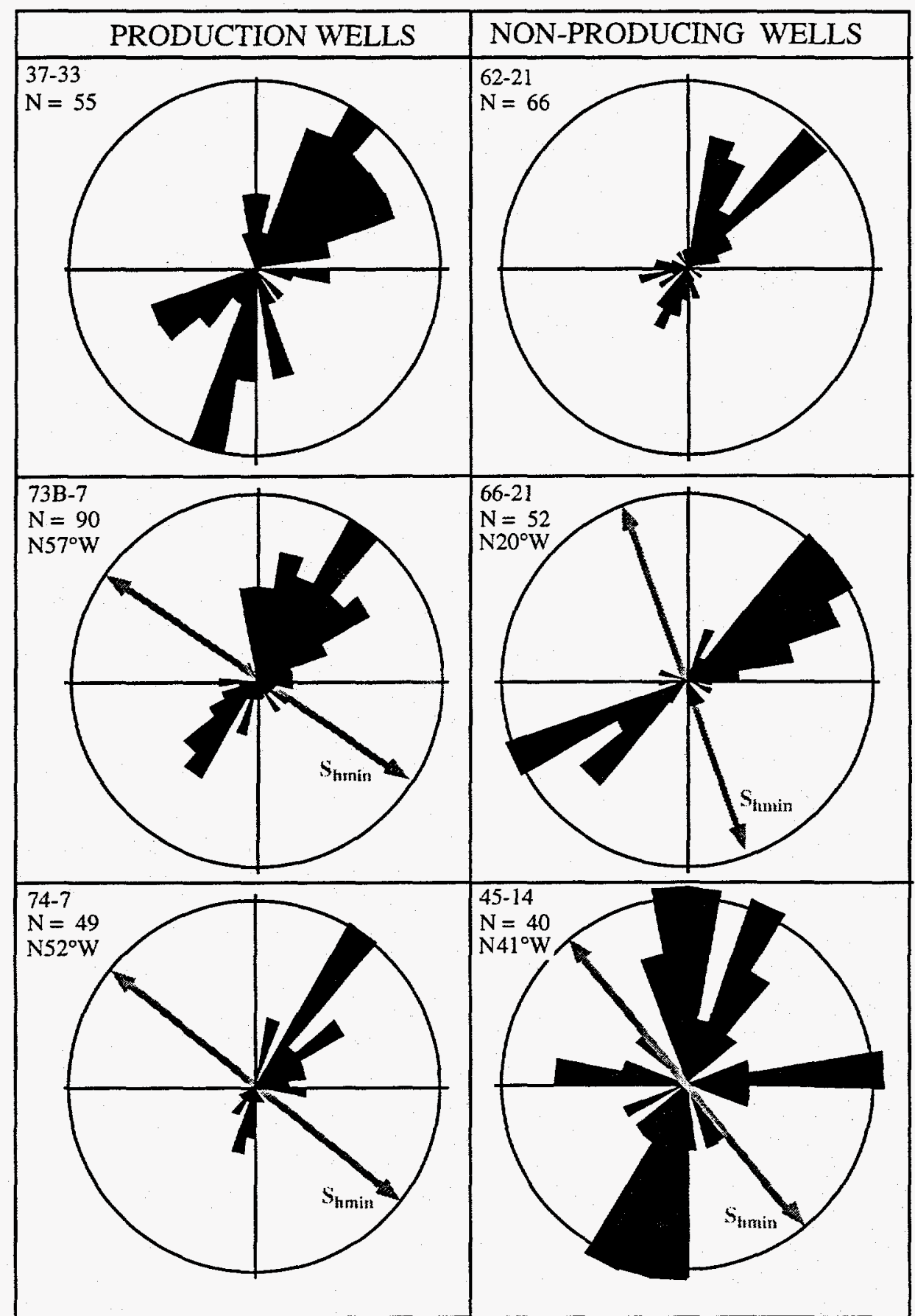

Figure 3. Histogram of the orientation of hydraulically conductive fractures along the producing segment of the Stillwater fault (left column) and conductive fractures measured along the non-productive fault segment (right column). Arrows indicate the orientation of $S_{\text {hmin }}$ after Hickman and Zoback (this volume).

74-7 and 37-33. Assuming the stress orientation measured in these nearby wells holds for well $62-21$ the set of producing fractures measured in this well is again a distinct subset of the overall fracture population and is orthogonal to the direction of $S_{\text {hmin }}$. 
As shown in Figure 2 the fracture populations in wells $62-21$ and 45-14 are somewhat different than the fracture populations measured in the other wells. Stress indicators in these wells suggest that although stress orientation remains roughly constant at distances of 5 to $8 \mathrm{~km}$ from the vicinity of the producing wells the magnitude of the maximum horizontal principal stresses, $S_{\mathrm{Hmax}}$, is much greater. The producing fractures in well 66-21 generally trend northeast as do the producing fractures in the other wells. In this case however, the population of producing fractures is not distinct from the overall northeast trend of all fractures in this well. In contrast, the producing fractures detected in well 4514 do not have a single well-defined orientation. They show more scatter than the overall north-northeast fracture trend for this well.

\section{COULOMB FAILURE ANALYSIS}

By utilizing results from hydraulic fracturing stress measurements and observations of wellbore failure in these wells (Hickman and Zoback, this volume) we have determined the proximity of the fractures and faults measured in these six wells to frictional failure. We used the Coloumb failure criterion to determine whether each fracture plane is a potentially active fault. As in the preceding analysis, (Barton et al., 1997) these fracture planes are assumed to be cohesionless. To apply the Coulomb criterion to these fractures, the orientations and magnitudes of the three in-situ principal stresses and the formation fluid pressure must be known. The shear stress and effective normal stress (i.e., $s_{N}-P_{P}$ ) acting on each fracture plane are then functions of the principal stress magnitudes, the fluid pressure, and the orientation of the fracture plane with respect to the orientations of the principal stresses (see Jaeger and Cook, 1976). As discussed by Barton et al., (1997), in computing the shear and effective normal stress acting on each of the fracture planes observed in the BHTV $\log$ from the study wells, we used linear approximations to the measured magnitudes of the three principal stresses and the formation fluid pressure.

Although $\mathrm{S}_{\mathrm{hmin}}, \mathrm{S}_{\mathrm{V}}$, and $\mathrm{P}_{\mathrm{p}}$ are well constrained at this site for all wells the magnitude of $S_{\mathrm{Hmax}}$ is poorly known. In the producing segment of the fault tensile failure provides constraints on the orientation of $S_{\text {Hmax }}$. The absence of wellbore breakouts in these wells places an upper bound on $S_{H_{\max }}$ magnitude (see Hickman and Zoback, this volume) and all we can say with certainty is that $S_{h \min } \leq S_{\text {Hmax }} \leq S_{v}$. Therefore, in this analysis of the fracture data from wells in the producing zone we assumed that $S_{\mathrm{Hmax}}$ at any given depth is equal to $\left(S_{h \min }+S_{V}\right) / 2$. For wells 73-B, 74-7, and 37-33 computing shear and effective normal stress over the full admissible range of $S_{\mathrm{H} \max }$ magnitudes, however, shows that whether or not a particular fracture is critically stressed for failure is relatively insensitive to the assumed $S_{H \max }$ value.

As discussed by Hickman and Zoback (this volume) the presence of wellbore breakouts in wells $45-14$ and 66-21 provides strong evidence that $S_{\text {Hmax }}$ is higher outside the producing zone than it is within the production zone. It has also been established that higher pore fluid pressures exist in wells 66-21 and 45-14. Using theoretical constraints on breakout initiation and available rock strength values the magnitude of $S_{\text {Hmax }}$ in the non-producing segments of the fault is actually greater than $S_{\mathrm{v}}$. The upper limit of $S_{\text {Hmax }}$ remains under investigation. For our frictional analysis of fractures measured in wells 45 14 and 66-21 (drilled into the non-productive segment of the fault) we assumed $S_{\mathrm{Hmax}} \approx \mathrm{S}_{\mathrm{V}}$ to account for the observed compressional wellbore failure which is not present in wells drilled within the production zone. We also used the observed elevated fluid pressure values for this analysis of fracture data from the nonproductive wells.

Using the stress orientations and magnitudes measured in these wells together with fracture orientations obtained from BHTV logs, we calculated the shear and normal stress on each of the fracture planes and used Coloumb failure criterion to determine whether nor not each plane was a potentially active fault. Based upon laboratory measurement of the frictional strength of prefractured rock (Byerlee, 1978), we assumed that fractures with a ratio of shear to normal stress $\geq 0.6$ are optimally oriented to the stress field for frictional failure. This analysis was performed for all fractures and for the subsets of hydraulically conductive fractures both within and outside the producing segment of the fault.

The results of this analysis are depicted as 3D Mohr diagrams of shear versus effective normal stress (see Jaeger and Cook, 1976), for the hydraulically conductive fractures inside the production zone and those drilled into the non-producing portion of the fault. (Figure 4). Conductive fractures from all wells in the producing segment of the Stillwater fault are nearly at optimal orientation for normal faulting.

The population of hydraulically conductive fractures in the producing zone lie between the Coloumb failure lines for $\mu=0.6$ and $\mu=1.0$ (Figure 4 , left 


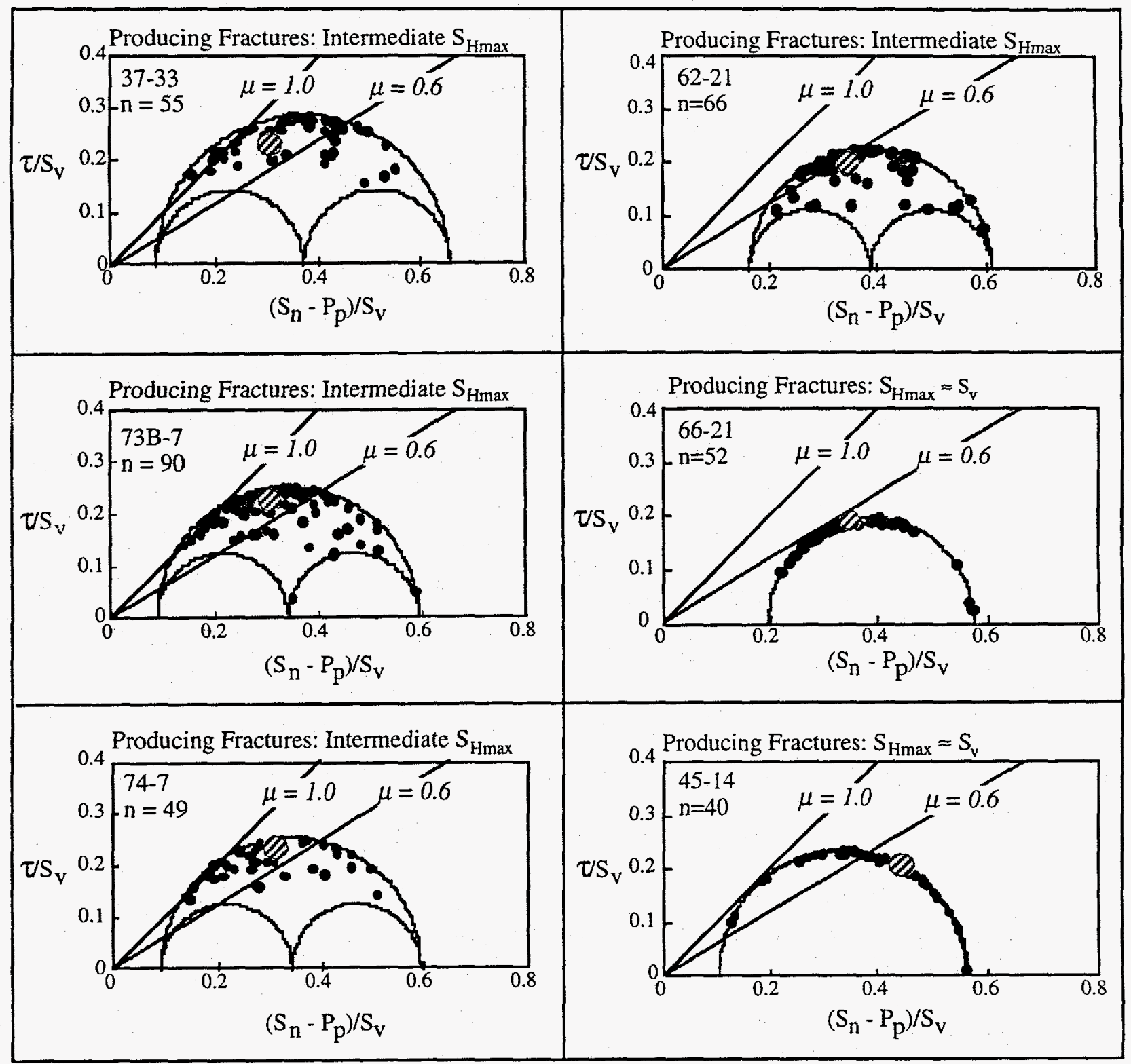

Figure 4. Normalized shear versus effective normal stress for hydraulically conductive fracture along the producing segment of the Stillwater fault (left column) and along its non-productive segment (right column) based on precision temperature logs (refer to Jaeger and Cook, 1979, p.28, for details of construction of these diagrams. Large black circles represent the shear and normal stresses for the Stillwater Fault at its intersection with each of the study wells.

column), these features are critically stressed, potentially active faults in frictional equilibrium with the current in-situ stress field at Dixie Valley.

Conversely, many of the hydraulically conductive fractures in the non-productive wells lie below the $\mu=0.6$ Coloumb failure curve (Figure 4 , right column) and therefore do not appear to be critically stressed shear fractures. Well 62-21 was not drilled into the Stillwater fault zone and can only provide background information on the state of stress at its location near the center of the valley. Based on the local stress orientations and magnitudes measured in wells $45-14$ and 66-21, the shear and normal stress on the Stillwater fault zone penetrated by these wells (shown as the large black circle in Figure 4) falls below the $\mu=0.6$ Coloumb failure line.

The Mohr circle constructed for the stress field measured in well 66-21 shows that all fractures are 
either tangent to or below the $\mu=0.6$ Coloumb failure line. This Mohr analysis indicates there is an insufficient ratio of shear to normal stress, even on well-oriented fracture planes, in this stress state to promote slip.

As discussed by Hickman and Zoback (this volume) the strike of the main fault changes by up to $40^{\circ}$ between its productive and non-productive segments. In the case of well 45-14 the local trend of the Stillwater Fault is quite different from its trend to the north, closer to the production zone. As $S_{\mathrm{H} \max }$ approaches $S_{\mathrm{V}}$ in this case the conditions for which a particular fracture is critically stressed for failure are quite sensitive to increased $S_{H \max }$ values. As a result, the Stillwater fault zone falls below its critical value for frictional failure (see Figure 4).

\section{CONCLUSIONS}

We have collected and analyzed fracture and fluid flow data made available by Oxbow Geothermal both within and outside the producing geothermal reservoir at Dixie Valley. Data from wellbore imaging and flow tests in wells outside the producing field that are not sufficiently hydraulically connected to the reservoir to be of commercial value provide both the necessary control group of fracture populations and an opportunity to test the concepts proposed in this study on a regional, whole-reservoir scale.

Results of our analysis indicate that fracture zones with high measured permeabilities within the producing segment of the fault are parallel to the local trend of the Stillwater fault and are optimally oriented and critically stressed for frictional failure in the overall ESE extensional stress regime measured at the site.

In well 66-21 the higher ratio of $S_{\mathrm{hmin}}$ to $S_{\mathrm{V}}$ appears to have the greatest effect on fracture permeability. In this case many of the fractures are optimally oriented by they are not critically stressed.

Evidence from well 45-14, where the Stillwater faults is severely misoriented for frictional failure, suggests that a necessary condition for high reservoir permeability is that the local orientation of the Stillwater fault zone be such that it is critically stressed for frictional failure in the measured stress field.

\section{REFERENCES}

Barton, C. A., S. Hickman, R. Morin, M.D. Zoback, T. Finkbeiner, J. Sass, and D. Benoit, In-situ stress and fracture permeability along the Stillwater Fault Zone, Dixie Valley, Nevada, In: Proceedings, Twenty-Second Workshop on Geothermal Reservoir Engineering, SGP-TR-156, Stanford University, Stanford, California, January 27-29, (1997).

Hickman, S., C.A. Barton, R. Morin, M.D. Zoback, T. Finkbeiner, J. Sass, and D. Benoit, Fracture permeability and its relationship to in-situ stress in the Dixie Valley, Nevada, Geothermal Reservoir, Int. J. Rock Mech. \& Min. Sci. 34:3-4, 126, (1997). Barton, C.A., M.D. Zoback and D. Moos. Fluid flow along potentially active faults in crystalline rock, Geology, 23, 8, 683-686 (1995).

Barton, C. A., L. Tesler, and M. D. Zoback, Interactive analysis of borehole televiewer data, in Automated pattern analysis in petroleum exploration, edited by I. Palaz and S. Sengupta, pp. 217-242, Springer-Verlag (1991).

Jaeger, J.C. and Cook, N. G. W., Fundamentals of Rock Mechanics (third Edition): New York, Chapman and Hall, p.28-30, 1979.

Kamb, W.B., Ice petrofabric observations from Blue Glacier, Washington, in relation to theory and experiment, J. Geophys. Res., 64, 1891-1910, (1959).

Okaya, D.A., and G. A. Thompson, Geometry of Cenozoic extensional faulting, Dixie Valley, Nevada, Tectonics, 4, 107-125, (1985).

Paillet, F. L., and P. Ollila, Identification, characterization, and analysis of hydraulically conductive fractures in granitic basement rocks, Millville, Massachusetts, Water Resources Investigations, U.S.G.S., WRI 94-4185, (1994).

Zemanek, J., E. E. Glenn, L. J. Norton, and R. L. Caldwell, Formation evaluation by inspection with the borehole televiewer, Geophysics, 35, 254-269, (1970). 